Michael J. Dueker

Michael J. Dueker is an economist at the Federal Reserve

Bank of St. Louis. Richard l. Jako provided research

assistance.

\title{
Hypothesis Testing with Near-Unit Roots: The Case of Long-Run
} Purchasing-Power Parity

$\boldsymbol{T}$ power of a given currency, like the dollar, will be equal actoss countries has strong appeal. If the hypothesis is true, then inflation and ex. change rate movements will be such that a given currency will, over time, lose equal amounts of its purchasing power in all countries. The sequence of events by which deviations from purchasing-power parity would be eliminated can best be illustrated by example: If the dollar could purchase more goods in other countries than in the United States, then U.S. consumers would purchase more goods from abroad, which would raise the demand for foreign currencies relative to the dollar and lead to a depreciation of the dollar and eventual equaliza. tion of the dollar's purchasing power across countries. Despite the intuitive appeal of such arguments for long-run purchasing-power parity, statistical tests have been mixed. This paper argues that previous test results have conflicted because tests of purchasing-power parity have relatively low power under both the null hypothesis that it holds, and the null that it fails. Hence this paper contains tests of both null hypotheses and shows that frequently neither is rejected for monthly data from five major industrialized countries. This result serves as a caution against testing only one null hypothesis, finding that the null hypothesis cannot be rejected for a broad set of countries and concluding that there is robust evidence for or against the theory of long-run purchasing-power parity.

The theory of long-run purchasing-power parity (PPP) implies that a currency's purchasing power is equal across countries in long-run equilibrium, but does not specify how long deviations from this equilibrium can last. Large and persistent departures from PPP in the last 20 years, however, have cast doubt on the validity of PPP. As we will discuss later, there is a literature which tests whether long-run Ppp holds, that is, whether departures from PPP are transitory. This article aims to reconcile some of the disparate results from previous studies by using a long-memory model, which can do more than classify deviations from PPP as temporary or permanent: it can provide specific measures of their persistence. Such measures are useful because large, persistent differences in a currency's purchasing power across countries can greatly affect trade flows and the allocation of resources.

Empirically, long-run PPp holds if the real exchange rate, which equals the nominal exchange rate multiplied by the ratio of the domestic and foreign price levels, is mean-reverting. This article will conform with the majority of the empirical PPP studies by using consumer price indexes 
to calculate the real exchange rate. If price indexes measured the prices of identical baskets of goods across countries, absolute ppp would hold if $\mathrm{P}^{*}=\mathrm{S} \times \mathrm{P}$, where $\mathbf{P}$ is the domestic price of the goods basket, $\mathrm{p}^{*}$ is the foreign price and $\mathrm{S}$ is the exchange rate in terms of units of foreign currency per unit of domestic currency. Because consumer price indexes do not measure the cost of identical baskets of goods across countries, however, relative PPP modifies the relationship to account for the ratio of the values of the two distinct baskets of goods: $\mathrm{P}^{*}=\mathrm{kSP}$, where $\mathrm{k}$ is the ratio of the value of the foreign basket to the domestic basket. The domestic country's real exchange rate with the foreign coumtry is then $1 / \mathrm{k}$ and equals $\mathrm{SP} / \mathrm{P}^{*}{ }^{1}$

The conventional approach to testing for long. run purchasing-power parity consists of testing for a unit root in the real exchange rate: Longrun PPP holds if the real exchange rate is meanreverting but not if it has a unit root. Previous tests have shown little power to reject whichever of the two null hypotheses is employed. Tests whose null hypothesis is that the real exchange rate contains a unit root generally fail to reject, whereas tests whose null is that long run PpP holds also often fail to reject. These disparate findings are reconciled, however, if there is long memory in the real exchange rate, which enables both acceptance and rejection of longrun PPP at conventional significance levels. ${ }^{2}$

This paper employs long-memory models to obtain estimates of the orders of integration of real exchange rates on a continuous scale. The advantage of estimating the order of integration on a continuous scale is that we can confirm that long-memory time series behavior in real exchange rates is a possible source of the discrepancies between previous tests of long-run ppp. The finding of long memory in real exchange rates also allows us to judge whether the real exchange rate reverts to its mean within an economically meaningful time frame.

\section{WHY PUCHASING-POWER PARTT MIGHT NOT HOLD}

Before discussing statistical tests of PPP, it is worth repeating Engel's (1992) list of possible reasons for the empirical failure of ppp:

1. Barriers to trade such as tariffs and transportation costs.

2. Different consumption preferences across countries.

3. The presence of non-traded goods in price indexes.

4. Prices which are sticky in terms of the currency in which the good is consumed.

Barriers to trade, such as tariffs, are an obvious reason why the same goods do not sell at the same price throughout the world. Different consumption preferences, on the other hand, would lead consumers in each country to choose different baskets of goods. Because price indexes are constructed for baskets of goods designed to represent a particular country's consumption, an apparent falure of PPP could be due to different rates of price inflation across two country's distinctive baskets of consumption goods, rather than different prices for the same goods across countries. When included in price indexes, non-traded goods can also muddle the interpretation of the real exchange rate, because non-traded goods can be idiosyncratic and are thus not directly comparable across countries. Nevertheless consumer price indexes will be used in this paper, despite the presence of non. tradeables, because wholesale price indexes can fail to reflect the underlying rate of inflation accurately. ${ }^{3}$ The fourth source of failure, sticky

\begin{abstract}
1Summers and Heston (1991) tabulate the costs of nearlyidentical baskets of goods across countries, rather than use existing price indexes. They define the PPP nominal exchange rate to be $P^{*} / P$ and use this implied exchange rate, rather than the market exchange rate, to make crosscountry comparisons. The Summers and Heston measures of the price levels could take the place of commonly used consumer price indexes when testing long-run PPP, as could wholesale price indexes. The Summers and Heston data, however, are only available on an annual basis and include data exirapolated between five year data collection periods. The analysis in this paper will be imited to the use of consumer price indexes to facilitate comparison with previous studies.
\end{abstract}

2Long memory, as will be discussed later, means that the order of integration of a time series process is greater than zero. If the order of integration is greater than 0.5 , the series is not covariance stationary and if the order of integration is greater than one, the series does not have a mean. Long memory is not the same as an autoregressive near-unit root, because a series with a near-unit autoregressive root is still integrated of order zero, and is not considered a long-memory process.

${ }^{3}$ For exampie the wholesale price index for Japan suggests that Japan has had deflation on average from 1980 to the present, whereas the GDP deflator and CPI show moderate inflation. 
prices, can best be explained by an example: Japanese autos sold in Japan and also exported to the United States have sticky prices in yen when sold in Japan and sticky prices in dollars when sold in the United States. Any exchange rate fluctuations would cause the yen (or dollar) price of the same model of car to differ across the Pacific. Thus autos might contribute to the failure of PPP in the true sense: the same good being sold at different prices (net of taxes) across countries.

\section{PREVIOUS TESTS OF PURGHASING-POWER PARTTV}

Tests of PPP in the literature can be classified according to many criteria. In this brief review of a large literature, three features will receive attention: 20th century annual data vs. post-1973 monthy data; the use of consumer price indexes versus wholesale price indexes in the calculation of the real exchange rate; and whether or not price levels are assumed to be measured with error. ${ }^{4}$ The ain of this review is to illustrate the lack of consensus that has emerged from studies of long-run PPP and identify which modeling choices might have influenced the outcomes of those tests.

Coughlin and Koedijk (1990) conduct unit-root tests on real exchange rates using post-1973 monthly data and consumer prices and find that the unit-root null hypothesis cannot be rejected. They also examine whether the real exchange rates are cointegrated with factors thought to determine the real exchange rate. Cheung and Lai (1993b) use post -1973 monthly data on consumer prices and allow for measurement error in prices. They use a Johansen (1991) likelihood ratio test for cointegrating vectors, in which long-run PPP is the null hypothesis, and generally fail to reject long-run PPP. ${ }^{5}$ Thus the studies of Coughlin and Koedijk (1990) and Cheung and Lai (1993b) illustrate the importance of the null hypothesis in testing long-run PPP. Edison and Fisher (1991) and Fisher and Park (1991) represent another pair of studies that differ in the null hypothesis employed and the general conclusions about long-run PPP. Cheung and

4For a thorough introduction to what the authors call the purchasing-power parity assumption, see Caves, Frankel and Jones (1990).

5provided that the nypothesis of zero cointegrating vectors has been rejected, the null hypothesis for subsequent hypothesis tests using the Johansen procedure is that there is at least one cointegrating vector.
Lai (1993a) study 20th century annual data and find evidence that the real exchange rate has long memory, but not a unit root for most countries studied. Pippenger (1993) uses wholesale price indexes and finds evidence that PPP between switzerland and various countries appears to hold in the long run.

Overall a lack of consensus emerges from empirical tests of long-run PPP. The choice of null hypothesis is one source of discrepancy, and it appears that results from a long-memory model can reconcile the apparently conflicting results of several previous studies of long-run PpP, which differ primarily in their choice of null hypothesis. Consequently, tests of each null hypothesis will be highlighted in the estimation results below.

\section{TESTING PURCHASING-POWER PARITY}

Much research on whether PPP holds in the long run consists of performing a unit-root test on the real exchange rate. It is well known, however, that unit-root tests, especially those having a unit root as the null hypothesis, like Dickey-Fuller, have little power against longmemory alternatives. Such unit-root testing con. sists of classifying economic variables as either integrated of order zero [I(0)] or one [I(1)]." In contrast, we use a parametric long-memory model in which data series, like the real exchange rate, are modeled as integrated of order $\mathrm{d}$, denoted I(d), where d does not have to be an integer. Any series that is integrated of order $\mathrm{d}<1$ will return eventually to its mean (or its deterministic trend), so shocks to the real exchange rate are not permanent if the real exchange rate is integrated of order $\mathrm{d}<1$.

This paper also provides information about the sources of PPP failure by examining the components of the real exchange rate. The ratio of the price levels may have a higher order of fractional integration than the nominal exchange rate, or vice versa. If $r$ is the real exchange rate, $s$ is the nominal exchange rate, $p$ is the domestic price level, and $p^{*}$ is the foreign price level (all in natural $\operatorname{logs}$ ), then $r=s+\left(p-p^{*}\right)$. If $s$ is I(d1), (p- $\left.\mathrm{p}^{*}\right)$ is $\mathrm{I}(\mathrm{d} 2)$, then $r$ will generally be in-

Eintegration of order one means that a variable's firsi differences are stationary, whereas its levels are not. 
tegrated of order $\max \{\mathrm{d} 1, \mathrm{~d} 2\}$. If $\mathrm{r}$ is $\mathrm{I}(\mathrm{b})$ where $\mathrm{b}<\max \{\mathrm{d} 1, \mathrm{~d} 2\}$, then the nominal exchange rate and the price ratio $\left(\mathrm{p}-\mathrm{p}^{*}\right)$ are fractionally cointegrated, that is, they share the same stochastic trend to some extent. ${ }^{7}$ The real $\mathrm{ex}$ change rate does not have a unit root if $b<1$.

We can also examine the point estimates of $\mathrm{d} 1$ and $\mathrm{d} 2$ and see which component appears to have the strongest trend. This comparison answers critics of flexible exchange rates who argue that floating rates actually have caused the real exchange rate to be less stable than it would have been under fixed nominal exchange rates. ${ }^{8}$ If $\mathrm{d} 1>\mathrm{d} 2$, then shocks to the nominal exchange rate are more persistent than shocks to the relative price levels. The latter is somewhat $\mathrm{cu}^{*}$ rious, because proponents of the switch to a flexible exchange rate regime envisioned flexible exchange rates as sources of real exchange rate stability in a world in which countries might have persistent differences in inflation rates. Yet if shocks to the nominal exchange rate are more persistent than shocks to the relative price levels, then the nominal exchange rate has persistence above what is potentially useful in reducing the variance of the real exchange rate. In the empirical results that follow, the possibility of excess persistence in the nominal exchange rate will be examined.

\section{BACKGROUND ON LONG- MEMORY MODELS}

For many time series, autoregressive movingaverage (ARMA) models serve as a parsimonious way to summarize the autocovariance structure of the data. One limitation of such models is that ARMA processes are integrated of order zero, and the autocovariances die off relatively quickly, even when a root in the autoregressive polynomial is near one. Thus ARMA models can be called short-memory models, because a shock affects the level of the series for a relatively short time.

Long-memory models, in contrast, are suitable for data that have slowly decaying coefficients in their moving-average representations. The fractional ARMA model can serve as a longmemory model, yet it adds only one parameter to a standard ARMA model. To illustrate, we begin with a simple ARMA(1,1) applied to the first difference of a data series $y$, where $L$ is the lag operator, $\varepsilon$ is a mean-zero disturbance, $\rho$ is the AR coefficient, and $\theta$ is the MA coefficient:

(1) $(1-\rho L)(1-L) \mathrm{y}=(1+\theta L) \varepsilon$

A fractional ARMA model is simply an ARMA model applied to fractionally differenced data:

(2) $(1-\rho L)(1-L)^{d y} y=(1+\theta L) \varepsilon$

The fractional differencing operator is evaluated by taking a Taylor series expansion around $\mathrm{L}=0:^{9}$

$$
\text { (3) } \begin{aligned}
\left(1-L^{\prime}\right. & =1-d L+\frac{d(d-1) L^{2}-}{2} \\
& \frac{d(d-1)(d-2) L^{3}+\ldots}{3 !}
\end{aligned}
$$

Two characteristics of fractionally integrated data are worth noting. First, a series that is integrated of order $\mathrm{d}$ (I(d)) with $\mathrm{d}<1$ reverts to its mean (or at least to its deterministic trend). Second, if $d<.5$, the series is covariance stationary. At first glance, it might seem counter-intuitive that a mean-reverting series can fail to be covariance stationary. With long memory, however, the departures from the mean can be sufficiently persistent that the variance of the series is infinite.

Furthermore, two commonly assumed datagenerating processes fit within the subset of fractional integration: trend and difference stationarity. Fractional integration offers a bridge between the controversial assignment of a data series as either trend or difference stationary, so that questions about stationarity assumptions

ular linear combination of two strongly trending series was

1(0).

For reasons outtined below the restriction that the coeticients on $s$ and $\left(\rho-p^{*}\right)$ equal one is relaxed, so that the order of integration of a general linear (cointegrating) combination of $s, p$ and $p^{*}$ is assumed to be the order of $i n-$ tegration of the real exchange rate. The concept of cointegration has been generalized [Granger (1986)] to include cases in which series have stochastic trends that only partially offset each other. This is called fractional cointegration. Originally, cointegration meant that a partic
FFor example, Aliber (1993) notes that "the U.S. dollar appreciated from 1979 to 1985 even though the U.S. inflation rate was higher than the inflation rates in Germany and Japan."

${ }^{9}$ The concept of fractional differencing was developed by Granger and Joyeux (1980) and Hosking (1981). 
may be avoided. For example, if $y$ is trend stationary, we might model $y$ as

(4) $y_{t}=\mu t+\varepsilon_{t}$

In differences, equation (4) looks like

(5) $(1-L) y_{1}=\mu+(1-L) \varepsilon_{1}$

If $y$ is difference stationary, then

(6) $\left(1-L y_{t}=\mu+\varepsilon\right.$,

Now suppose that $y$ is fractionally integrated of order $\mathrm{d}$. The first differences of $y$ are then equal to

(7) $(1-L) y_{t}=\ddot{\mu}+(1-L)^{t-d} \varepsilon_{t}$

where $\tilde{\mu}$ is proportional to $\mu$. Clearly trend stationarity $(d=0)$ and difference stationarity $(d=1)$ are bridged by fractional integration, which allows for intermediate cases. An intuitive way to understand why fractional integration is an intermediate case between trend and difference stationarity is to interpret each shock in a difference-stationary process to be a permanent shift away from any previous trend; a shock in a trend-stationary process is a short-lasting shift from the trend; a shock in a fractionally integrated process is a long-lasting shift from the trend. This paper uses estimates of the order of fractional integration to discriminate, if possible, between longlasting shifts from the mean real exchange rate and permanent shifts in the real exchange rate (the unit-root case).

\section{ESTIMATES OF LONG MEMORY IN REAL EXCHANGE PATES}

The data used in this article consist of 234 monthly observations of the nominal exchange rates and consumer price indexes for the Lnited States, Great Britain, Germany and Japan from June 1973 to November 1992. ${ }^{10}$ Thus six bilateral relationships will be examined.

Fractional ARMA models are used to estimate the orders of integration of the nominal exchange rates, the ratios of the price levels and the real exchange rates. The general form of the fractional ARMA model is

(8) $A(L)(1-L)^{d} y_{t}=B(L) \varepsilon_{t}$

where $y$ is $l(d)$ and $\varepsilon$ is assumed to have zero mean, no serial correlation and variance $\sigma^{2}$. $A(\mathrm{~L})$ is an autoregressive polynomial of order $\mathrm{p}$ and $B(L)$ is a moving average polynomial of order $q$ :

(9) $A(L)=1-\rho_{1} L-\rho_{2} L_{i}^{2}-\ldots-\rho_{p} L^{P}$

(10) $B(L)=1+\theta_{1} L+\theta_{2} L^{2}+\ldots+\theta_{q} L^{4}$

Estimation was carried out using the Fox and Taqqu (1986) frequency-domain estimator of fractional ARMA models. The estimator is based on an approximation to the likelihood. Dahlhaus $(1988,1989)$ has analyzed the Fox and Taqqu esfimator and has shown that it shares the same asymptotic efficiency as exact maximum-

likelihood estimation. Further details regarding the estimator appear in the appendix.

Before presenting estimation results, we must discuss how the real exchange rate was calculated. Any mismeasurement of the price levels can lead to spurious changes in the mean of the real exchange rate and bias tests toward rejec. tion of long-run PPP. To minimize the possibility of spurious rejections of long-run PPP, the real exchange rate was calculated by estimating a fractionally cointegrating relationship between the nominal exchange rate ( $s$ ), the domestic price level $(p)$ and the foreign price level $\left(\mathrm{p}^{*}\right):{ }^{11}$

$$
\text { (11) } s_{i}=\alpha_{0}-\alpha_{1} p_{i}+\alpha_{2} p_{i}^{*}+\varepsilon_{i}
$$

The residuals from equation (11) were then treated as the real exchange rate for unit-root testing with the fractional ARMA model. Cheung and Lai (1993b) and Pippenger (1993) also estimate a general cointegrating relationship, rather than impose $\alpha_{1}=\alpha_{2}=1$. They both argue that, because of measurement error in price indexes and unequal weights attached to the same good in different indexes, it is undesirable to impose unit coefficients on the price indexes when studying whether the real exchange rate is mean-reverting. The Phillips and Hansen (1990)
1oKoedik and Schotman (1989) find that the real exchange rates between 15 industrialized countries are fairly well spanned by the real exchange rates between the United States, Japan, Germany and Great Britain.
"Cheung and Lai (1993a) discuss the asymptotic theory behind estimating regressions where the residuals are tractionally integrated. 
Table 1

Estimated Orders of Integration

\begin{tabular}{|c|c|c|c|c|}
\hline countries & $\begin{array}{l}\text { refal exchange } \\
\text { rale }(0)\end{array}$ & tortatistic & $\begin{array}{l}\text { Norrinal exchange } \\
\text { rate (di) }\end{array}$ & $\begin{array}{l}\text { Price ratio } \\
\text { (ca) }\end{array}$ \\
\hline Whited slates & 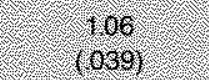 & -154 & 1031 & $\begin{array}{l}160 \\
(043)\end{array}$ \\
\hline $\begin{array}{l}\text { Writed slates } \\
\text { Grimany }\end{array}$ & .903 & 146 & $\left(\begin{array}{r}17 \\
(028)\end{array}\right.$ & $(1881$ \\
\hline $\begin{array}{l}\text { United states } \\
\text { Happan. }\end{array}$ & 106 & 658 & 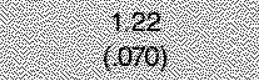 & $\left(\begin{array}{r}62 \\
(080)\end{array}\right.$ \\
\hline $\begin{array}{l}\text { Whied kivgdom. } \\
\text { Germant. }\end{array}$ & $(672$ & 272 & $(1052$ & 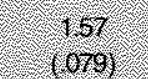 \\
\hline Writed vingeorn & $(0.64)$ & 5.589 & $(1038)$ & 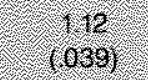 \\
\hline Germant & $(267$ & 1028 & $(2,149$ & $(096)$ \\
\hline
\end{tabular}

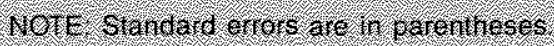

method of estimating cointegrating relationships was used for equation (11). This method ac. counts for simultaneity in the determination of left- and right-hand side variables. Cheung and Lai (1993b) suggest using estimation procedures that take into account interactions between left. and righthand side variables. In fact, the Phillips-Fansen estimates of $\alpha_{1}$ and $\alpha_{2}$ indicate that they should not be restricted to equal one. For example, for the nominal exchange rate be tween Britain and the United States, the estimates of $\alpha_{1}$ and $\alpha_{2}$ are 1.45 and 1.22 , respectively.

The next point of focus is the null hypothesis to be tested: PPP holds as the null hypothesis if the hypothesis that $b<1$, where $b$ is the order of integration of the real exchange rate, is not rejected; the alternative null hypothesis that PPP fails is not rejected if the null that $b \geq 1$ is not rejected. Using the fractional ARMA model it is easy to test both null hypotheses and show how the results depend on the choice of the null.

Table 1 contains the main results on the estimated orders of integration of the relevant series. Simple t-tests can be used to test for long-run PPP by dividing one minus the estimat. ed order of integration of the real exchange rate by its standard error. Doing this, we see that the null hypothesis that $b<1$, where $b$ is the order of integration of the real exchange rate, is rejected for only two of the six pairs: Lnited States/Japan and Britain/Japan. These are the significantly negative t-statistics in table 1 . rhitus long-run PPP is not rejected as a null hypothesis in four of six cases. If we reverse the null, however, we can reject the null that $b \geq 1$ for only one pain: Britain/Germany, ${ }^{12}$ This is the significantly posive t-statistic in table 1 . The results for United States/Germany are borderline with a 4 statistic of 1.45 , bat this is not significant at the usual 5 percent level of significance in a onentaled t-test, where the critical value is 1.658 .

Overall, the orders of integration of real $\mathrm{xx}^{-}$ change rates are often close enough to one that neithe: null hypothesis is rejected. This explains some discrepancies between past tests of longrun PPP. Coughlin and Koedijk (1990) used Dickey-Fuller unit-root tests on real exchange rates and could not reject the null that long-rum ppp fails to hold. Cheung and Lai (1993b), on the other hand, tested the null that long-rum PPP holds and did not find many rejections of long-run PPP. 'The results from the long-memory model reconcile these findings.

The estimates from the long-memory models do more than give unit root tests, however, by 
providing an estimate of the order of integration of the real exchange rate on a continuous scale. Whichever null is used, one result is clear: Even if long-run PPP holds, it is very slow in developing. Assuming that the order of integration of the real exchange rate is $0.9,73$ percent of a shock is still present after 12 months; 68 percent after 24 months; 65 percent after 36 months; and 63 percent after 48 months. As a practical matter, it seems fair to conclude that PPP does not hold within a time horizon that is economically relevant. Uncovering this type of information is the chief advantage of estimating the order of integration on a continuous scale. With other unit-root testing methods, we are forced to view a series as being either I(0) or I(1). Such a polar characterization may not provide practical information about the persistence of the shocks.

Table 1 also provides information about the persistence of shocks to the nominal exchange rate relative to shocks to the ratio of the price levels. In five of six cases, point estimates suggest that the nominal exchange rate has a lower order of integration than the price ratio. ${ }^{13}$ For Britain/Japan the point estimate of the order of integration is 1.15 for the nominal exchange rate vs. 1.12 for the price ratio, but this difference does not appear to be statistically significant. ${ }^{14}$ Thus the conjecture that nominal exchange rates in the post-Bretton Woods era have shown excess persistence appears to be false. In general, greater persistence in the nominal rate would be needed to offset the persistence in the price ratios for the real exchange rate to be rendered $\mathrm{I}(0)$. This is because no $\mathrm{I}(0)$ linear combination can exist, for example, between a series that is $I(.8)$ and one that is $I(.2)$. The series that is I(.2) does not have enough of a trend with which to offset the relatively strong trend in the variable that is $I(.8)$.

Another finding from table 1 is that inflation differentials are fractionally cointegrated in some cases. For example, the estimates indicate that $\left(p_{t i s}-p_{s p_{N}}\right)$ is $1(1.62)$ and $\left(p_{t S}-p_{t K}\right)$ is $\mathrm{I}(1.60)$, but the difference $\left(p_{\varepsilon K}-p_{J P}\right)$ is only I(1.12). This means that the inflation differentials between the United States and Britain and between the
United States and Japan appear much more persistent than the inflation differential between Britain and Japan. In other words, inflation rates in Britain and Japan come closer to sharing a common trend with each other than with inflation in the United States.

Tables 2 through 4 report the fractional ARMA parameter estimates fully only for the bilateral relationships for the United States for the sake of brevity. The key result in these tables is that in fractional ARMA models the fractional differencing parameter can capture the long-run behavior of the data, freeing $A R$ parameters to match the short-run dynamics. If, on the other hand, an ARMA model instead of a fractional ARMA model were fit to the data, the autoregressive polynomial would be forced to have a near-unit root.

In table 2 several AR parameters are negative, and the largest equals 0.53 in the fractional ARMA model of the ratio of the price levels between the United States and Britain. In table 3 both estimated AR parameters for the nominal exchange rate between the United States and Germany are negative, implying that all positive dependence in the exchange rate beyond the first lag is due to the large positive value of the fractional-differencing parameter. The largest root in an AR polynomial in table 3 is 0.37 , which is far from the unit circle, in the real exchange rate between the United States and Germany. Estimates of the model of the reat exchange rate between the United States and Japan, found in table 4, also show two negative AR coefficients. In fact all of the AR polynomials in table 4 have roots with real parts that are very far from the unit circle. They are -.05 , -.03 , and .08 , respectively, for the real exchange rate, the nominal exchange rate and the price ratio. With the inclusion of the fractional differencing parameter, the AR parameters can take values which allow the fractional ARMA model to capture both long-run dependence and short-run dynamies in the data. The shaded insert and figures 1 through 3 provide a visual check of the match between the covariance structure of the data and that implied by the estimated fractional ARMA model.

\footnotetext{
${ }^{13}$ An order of integration above one for variables in logs means that the growth rates display long memory. In the case of the price ratio, the corresponding growth rate is the infation differertial across the two countries. For the nominal exchange rate, it is the rate of exchange rate appreciation.
} 


\section{Table 2}

\section{Fractional ARMA Models: United States-United Kingdom}

\begin{tabular}{lll}
\hline & \\
\hline
\end{tabular}

\section{Table 3}

\section{Fractional ARMA Models: United States-Germany}

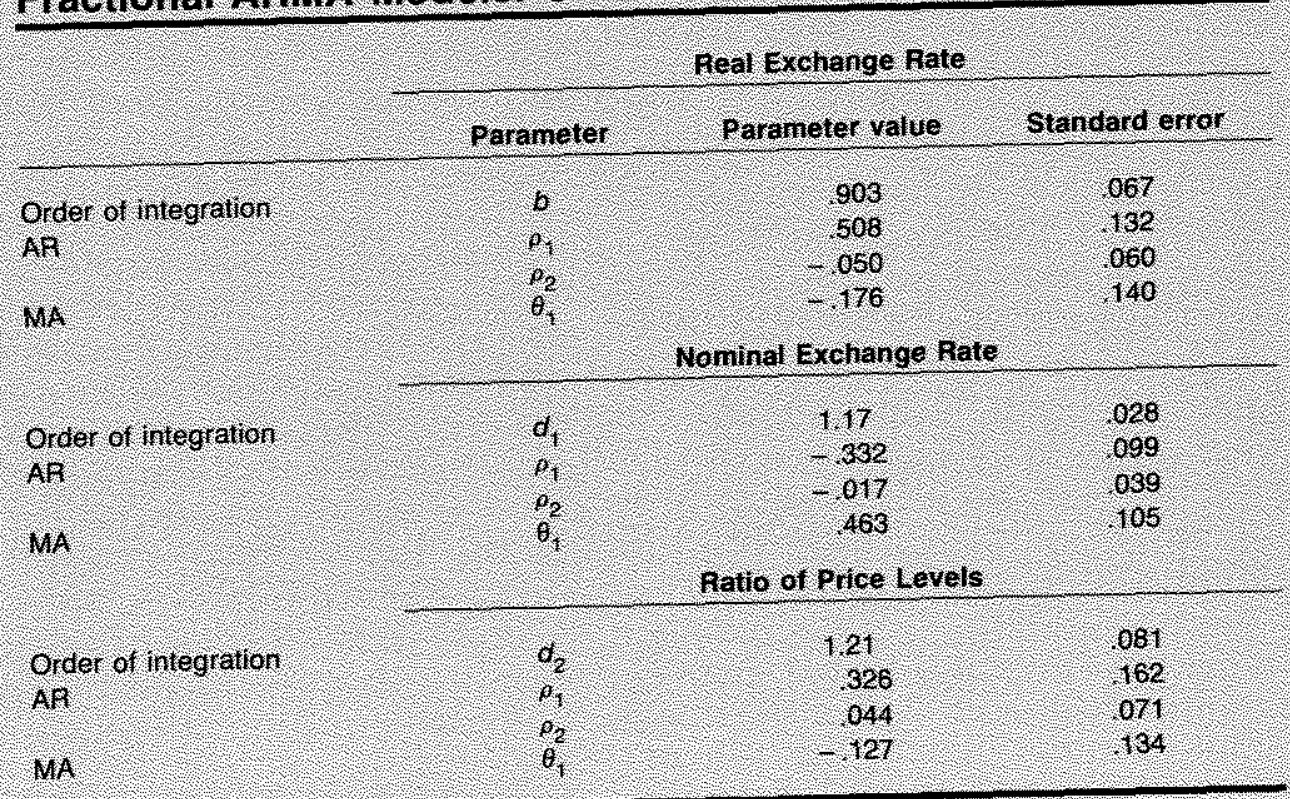


Table 4

Fractional ARMA Models; United StatesJapan

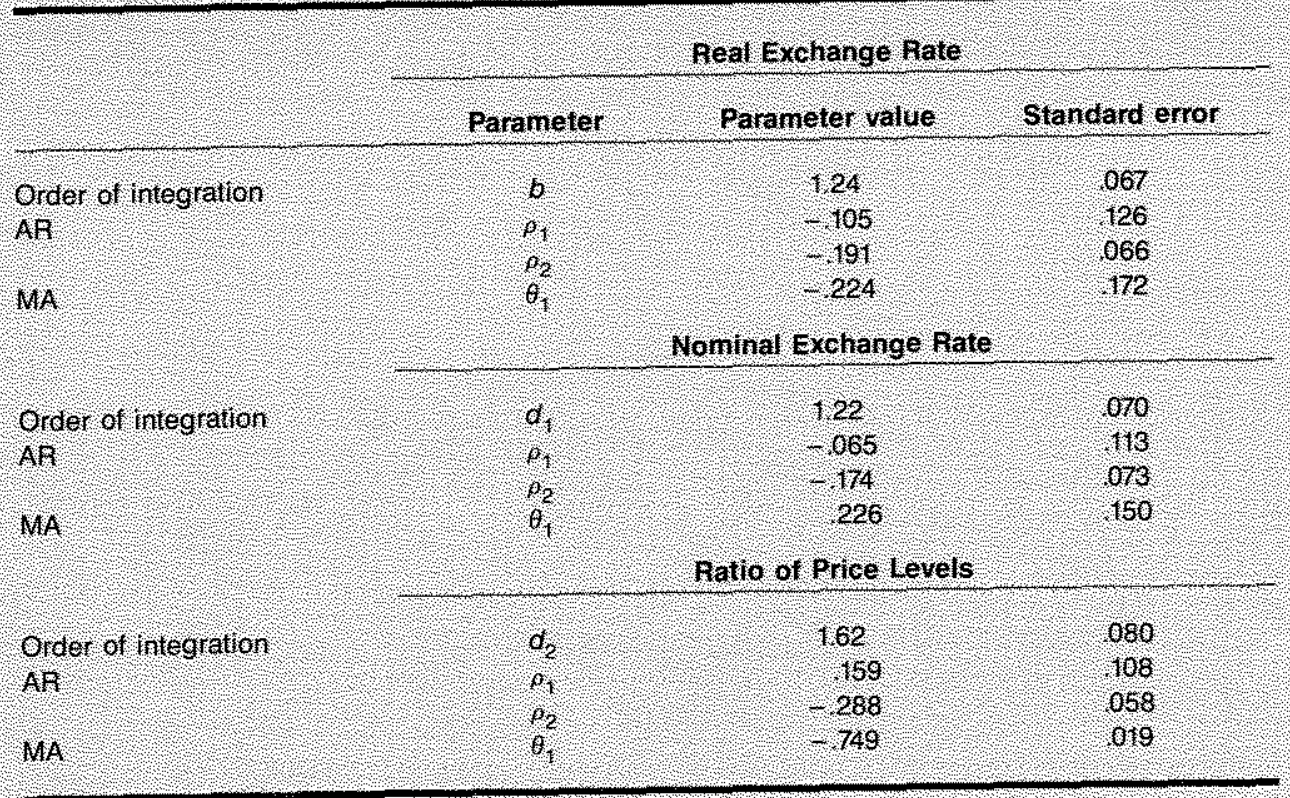

\section{A Visual Check of the Results}

Gree a. hactional a rilt model has been es thated, a visual diagnostic dheck of lhe afle. guact or lie sperifiction and estimates con be obtanced by looking at a jolot of the pel 10 dogram ef the data alongside a plot of the spedtal density inj lied by the sperified hac. lignal A RWA nodel, if his nodel fits hie lata well he wo grophe will have the same generd thwing polnts. the area mider bhe

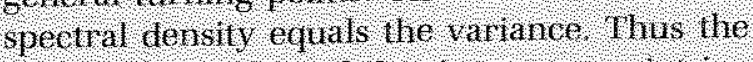
herght of whe spectual densivy at any point if elicates how nuch of he varianee is dive 10 cycles of that hequenet $1 \mathrm{~h}$ hiss way $1 \mathrm{he}$ speetral density summarties he autocovarl ance strueture lighes 1 hrough 8 provide a took at the lhree data series for the Yhited Stales Getmany the real exchange rate, the nominal exchange rate and the pries ratio. The figures show that the estmated fractional ARMA nodels roughty envelope the smoothed

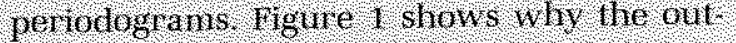
come of athe whit loor lest on the US. Germary r ed exchange rate is logrderline it is unelear whether the yptwin in the smoothed periodogram at very low frequencles it sig. nifteant or whether lie point estinate of a

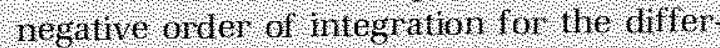
enced real exchange late is norrect t que other thing to note is that withoul A AMA parameters the nodel would be able $10 \mathrm{fft}$ onty series that have globally coneave for

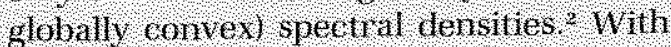

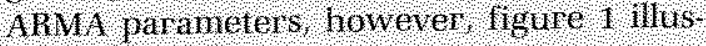
trates hat a fractional ArMA A an generate turming points in the spectial density the bestritting glebaly concave spectral lensily would obviously provide a nuen less satisfac tory 71 or lhe US Germany real exchange rate than he one with terning points shown $11 \mathrm{gure} 1$
In weon the disthation is clear A series with a nega. tive order of fractional integration will have a spectral censity valle of zelo at requency zero, a seres with a positive order of fractional integration will have a spectral density value of infinity at frequency zero. For ticures 2 and 3 , is clear from the periodogram itat the series have positive orters of ntegration this 15 not cleat for the real exchange rate in tgure 1
Whthout ARMA parameters, the frolional ARMA nodel is cafled he tractional nolse nodel its spectal densily is globaly concave if the tractional differencing parameter from equation (2) is negative; it is globally conver if he fractional diferencing parameler is positive 
Figure 1

Spectrum of Differenced Real Exchange Rate: U.S./Germany

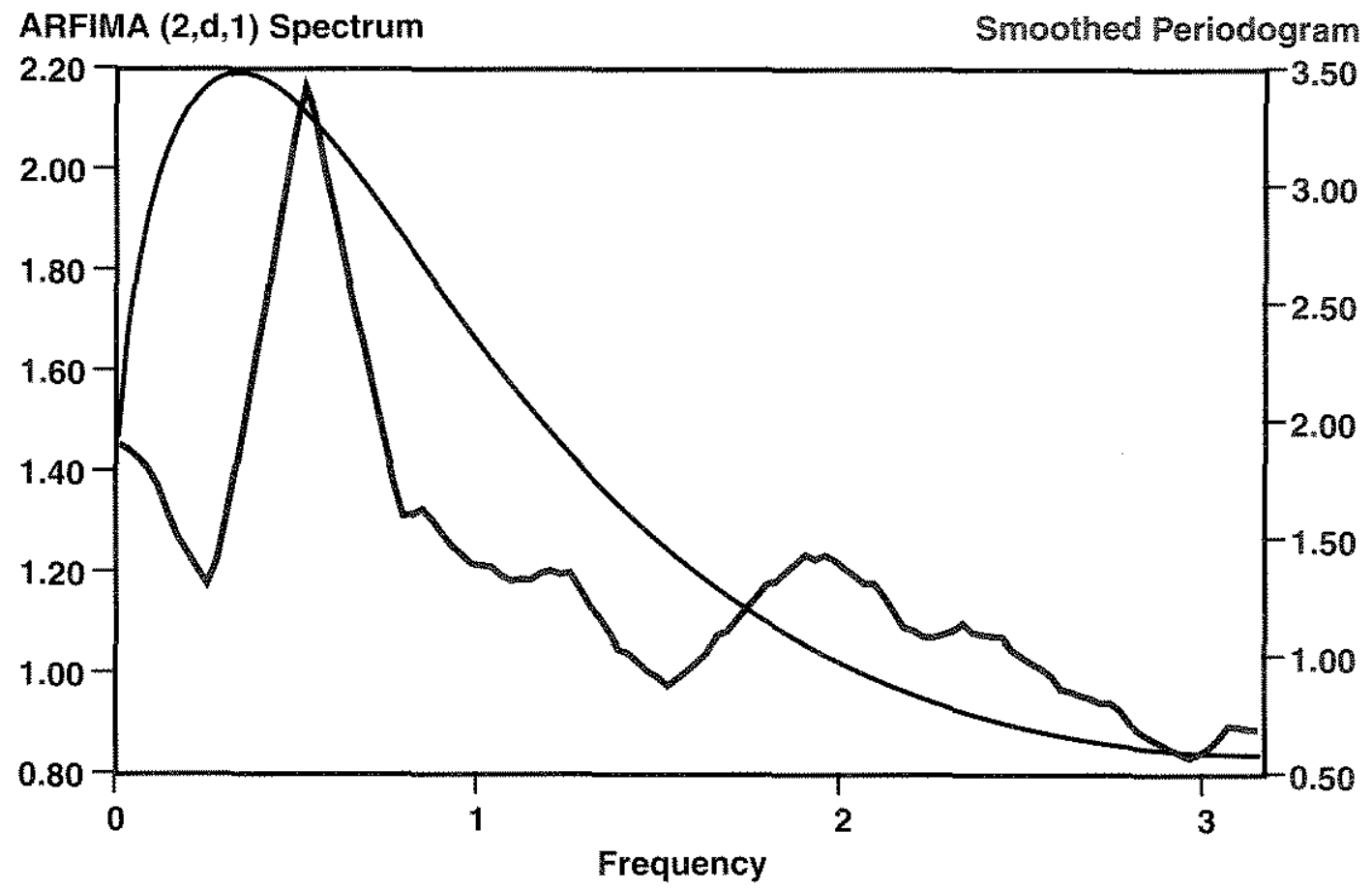

Figure 2

Spectrum of Differenced Nominal Exchange Rate: U.S./Germany

ARFIMA (2,d,1) Spectrum

Smoothed Periodogram

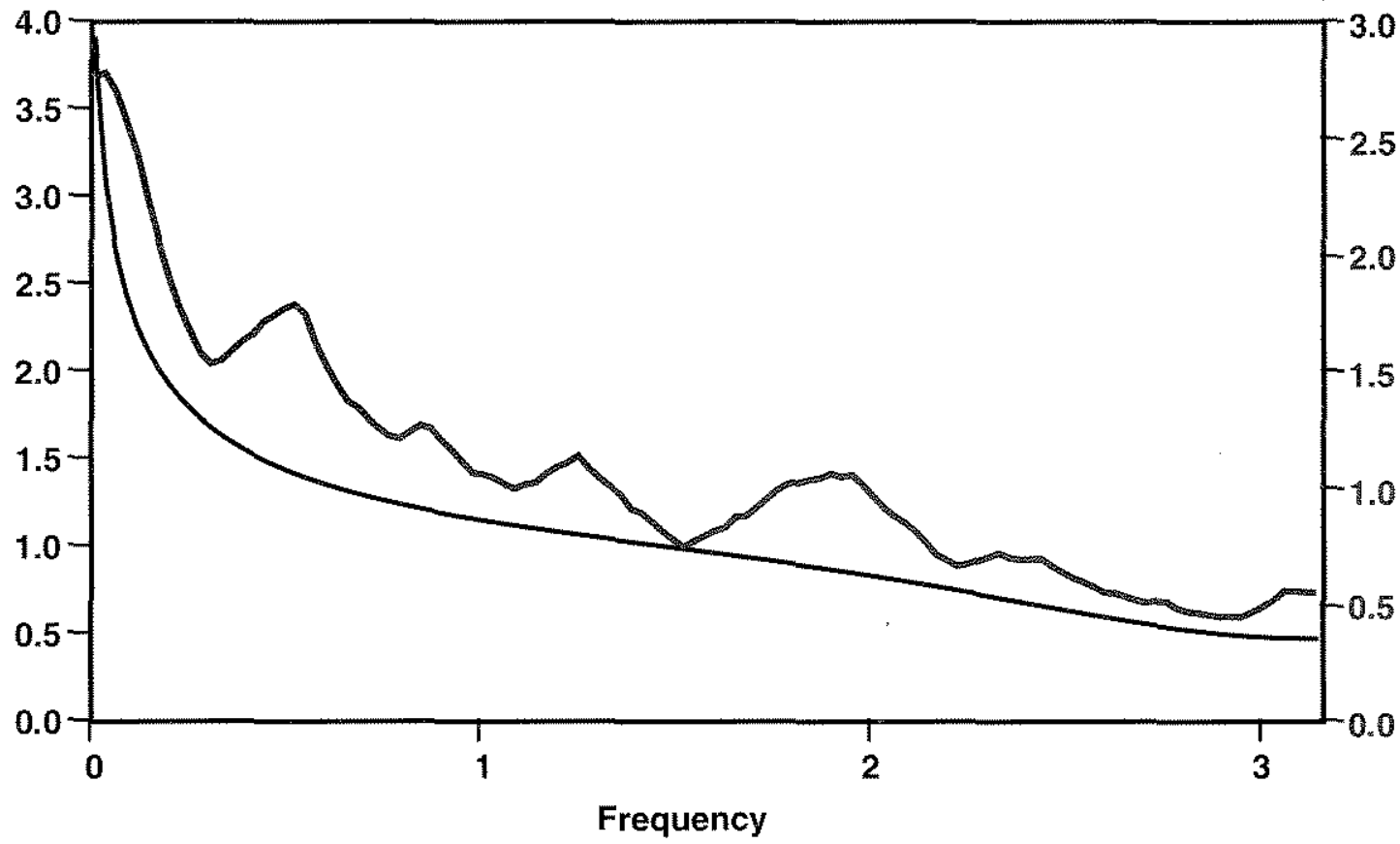




\section{Figure 3}

\section{Spectrum of Differenced Price Level Ratio: U.S./Germany}

ARFIMA $(2, d, 1)$ Spectrum

Smoothed Periodogram

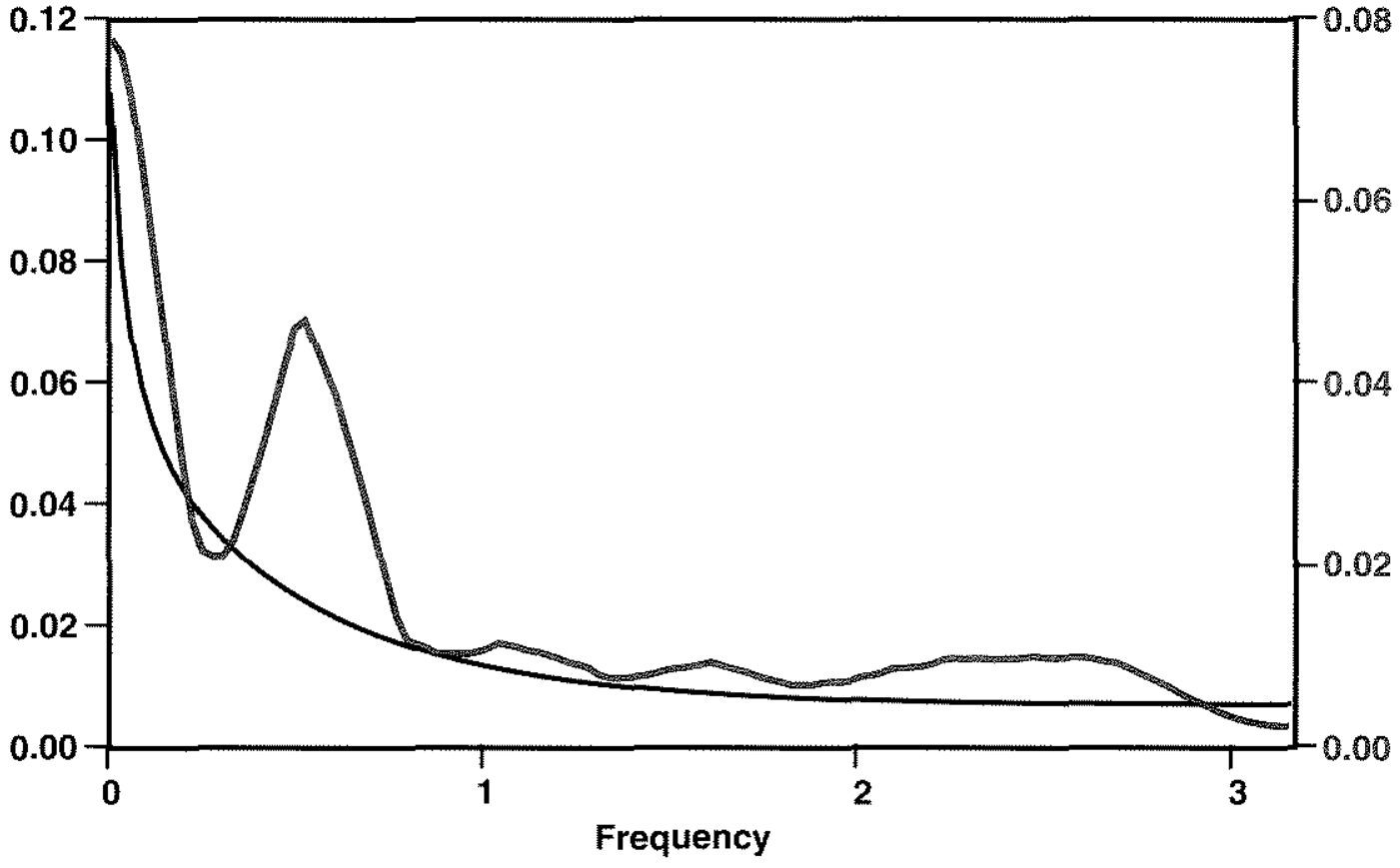

\section{CONCLUSIONS}

This article illustrates the key role played by the null hypothesis in testing for unit roots in real exchange rates. If $b$ is the order of integration of the real exchange rate, then the null that $b \geq 1$ is difficult to reject, in which case one would presume that long-run purchasing-power parity does not hold. When the null is that $b<1$, we also find few rejections, so long-run PPP apparently holds. When this type of ambiguity appears, it is helpful to estimate the ord er of integration on a continuous scale. The fractional ARMA models presented here do this and the standard errors on $b$ for the six real exchange rates studied show that even if $b<1$, it is not far enough away from one to make a strong case that purchasing-power parity is empirically relevant.

\section{PERTERECLS}

Aliber, Rober: Z. "The Case for Flexible Exchange Rates Revisited," unpublished manuscript, University of Chicago (Apri] 1993).

Caves, Fichard E., Jeffrey A. Frankel and Ronald W. Jones. World Trade and Payments: An Introduction (Scott,Foresman, 1990).
Cheung, Yin-Wong. "Long Memory in Foreign Exchange Rates," Joumal of Business and Economic Statistics (January 1993), pp. 93-101.

Cheung, Yin-Wong, and Kon S. Lai, "A Fractional Cointegration Analysis of Purchasing Power Parity:" Joumal of Busjness and Economic Statistics (January 1993a), pp. 103-12.

"Long-Run Purchasing Power Parity during the Recent Float," Joumal of international Economics (February 1993b), pp. 181-92.

Chowdhury, Abdur R., and Fabio Sdogati. "Purchasing Power Parity in the Major EMS Countries: The Role of Price and Exchange Rate Adjustment," Journal of Macroeconomics (Winter 1993), pp. 25-45.

Coughlin, Cletus C., and Kees Koedijk. "What Do We Know About the Long-Run Real Exchange Rate?" this Review (January/February 1990), pp. 36-48.

Dahlhaus, Rainer. "Small.Sample Effects in Time Series Analysis: a New Asymptotic Theory and a New Estimate," Annals of Statistics (Volume 1b, 1988), pp. 808-41.

"Efficient Parameter Estimation for Self-Similar Processes," Annals of Statistics (Volume 17, 1989), pp. $1749-66$

Dickey, David A., and Wayne A. Fuller. "Likelihood Ratio Statistics for Autoregressive Time Series with a Unit Root," Econometrica (July 1981), pp. 1057-72.

Diebold, Francis $X$., and Glenn D. Rudebusch. "Long Memory and Persistence in Aggregate Outpu:" Journal of Monetary Economics (September 1989), pp. 189-209.

Edison, Hali J., and Eric O'N. Fisher. "A Long"Run View of the European Monetary System," Joumal of International Money and Finance (March 1991). pp. 53-70. 
Engel, Charles. "Real Exchange Rates and Relative Prices: An Empirical Investigation," NBER Working Paper No. 4231 (December 1992).

Engel, Charles, and James D. Hamiton. "Long Swings in the Dollar: Are They in the Data and Do Markets Know It?" American Economic Review (September 1990), pp. $689-713$.

Fisher, Eric O'N., and Joon Y. Park. "Testing Purchasing Power Parity Under the Null Hypothesis of Co-Antegration," Economic Journal (November 1991), pp. 1476-84.

Fox, Rort, and Murad S. Taqqu. "Large Sample Properties of Parameter Estimates for Strongly Dependent Stationary Gaussian Time Series," Annals of Statistics (Volume 14. 1986), pp. $517-32$.

Granger, CW.J. "Developments in the Study of Cointegrated Economic Variables," Oxford Bulletin of Economics and Statistics (August 1986), pp. 213-28.

Granger, CW.J, and Roselyne Joyeux. "An Introduction to Long-Memory Models and Fractional Differencing," Jourhal of Time Series Analysis (Volume 1, 1980), pp. 15-29.

Hakkio, Craig $S$. "Does the Exchange Rate Follow a Random Walk? A Monte Carlo Study of Four Tests for a Random Walk." Journal of Intenational Money and Finance (June 1986), pp. 221-29.

Hosking, J.R.M. "Fractional Differencing," Biometrika (Volume 1b, 1981), pp, 165-76.

Hsieh. David A. "The Determination of the Real Exchange Rate: the Productivity Approach;" Joumal of infernational Economics (May 1982), pp. 355-62.

Huizinga, John. "An Empirical Investigation of the Long-Run Behavior of Real Exchange Rates," Carnegie-Rochester Conference on Public Policy (Autumn 1987), pp. 149-214.
Johansen, Soren. "Estimation and Hypothesis Testing of Cointegrating Vectors in Gaussian Vector Autoregressive Models," Econometrica (November 1991), pp. 1551-80.

Koedikk, Kees, and Peter Schotman. "Dominant Real Exchange Rate Movements;" Journal of International Money and Finance," (December 1989), pp. 517-31.

McNown, Robert, and Myles S. Wallace. "National Price Levels, Purchasing Power Parity, and Cointegration: A Test of Four High Inflation Economies," Journal of international Money and Finance (December 1989), pp. 533-45.

Phillips, Peter C.B., and Bruce E. Hansen. "Statistical Inference in Instrumental Variables Regression with $\mathrm{f}(1)$ Processes," Review of Economic Studies (January 1990), pp. $99-125$.

Pippenger, Michael K. "Cointegration Tests of Purchasing Power Parity: The Case of Swiss Exchange Rates," Journal of International Money and Finance (February 1993), pp. 46-61.

Sowell, Fallaw. "Maximum Likelihood Estimation of Stationary Univariate Fractionally integrated Time Series Models;" Journal of Econometrics (July-September 1992a), pp. $165-88$.

"Modeling Long-Run Behavior with the Fractional ARIMA Model," Journal of Monetary Economics (Aprif 1992b), pp. 277-302.

Summers, Fobert, and Alan Heston. "The Penn World Table (Mark 5): An Expanded Set of Intemational Comparisons, 1950-1988," Quarterly Journal of Economics (May 1991), pp. $327-68$.

Tayior, Mark P. "An Empirical Examination of Long-Run Purchasing Power Parity Using Cointegration Techniques," Applied Economics (October 1988), pp. \$369-81.

Whitt, Joseph A. Jr. "Nominal Exchange Rates and Unit Roots: A Reconsideration." Joumal of International Money and Finance (December 1992), pp. 539-51.

\section{Appendix: \\ The Fox and Taqqu Estimator}

Dahlhaus (1988) discusses why the Fox and Taqqu (1986) frequency domain estimator is an approximate maximum-likelihood estimator, sharing the same optimality properties as exact maximum-likelihood estimation. The Fox and Taqqu estimator is derived from the following minimization problem:

(12) $\min \sum_{\operatorname{di}_{k}}\left[\ln \left(\sigma^{2} f\left(\lambda_{k} ; \theta\right)\right)+\frac{I\left(\lambda_{k}\right)}{\sigma^{2} f\left(\lambda_{k} ; \theta\right)}\right]$

where $I\left(\lambda_{k}\right)$ is the vector of periodogram ordinates of the data and $\sigma^{2} f\left(\lambda_{k}\right)$ is the spectral density function implied by the parameterized model. For the fractional ARMA model in equation (8), the spectral density equals

(13) $f(\lambda)=\frac{\left|B\left(e^{i \lambda}\right)\right|^{2}}{\left|A\left(e^{i \lambda}\right)\right|^{2}}\left(1-e^{i \lambda}\right)^{-d}\left(1-e^{-i \lambda}\right)^{-d}$,

where $A$ and $B$ are polynomials defined in equations (9) and (10). The objective function is minimized with respect to $\theta$ and $\sigma^{2}$. An intuitive description of the objective function is that one wants to choose parameters that will make the spectral density function implied by the model look like the periodogram of the data. 